\title{
Inconsistências entre as Estimativas de Emissões de Gases de Efeito Estufa dos Transportes e o Plano Municipal de Mobilidade Urbana de Manaus
}

\author{
Inconsistencies between Estimated Transport Greenhouse Gas Emissions and \\ Urban Mobility Plan of Manaus City.
}

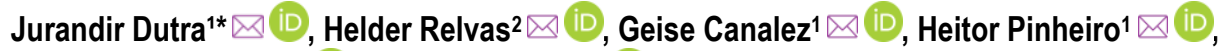 \\ Andrea Waichman $1 \otimes$ (iD), Myriam Lopes ${ }^{2} \varangle$ (iD \\ ${ }^{1}$ Centro de Ciências do Ambiente, Universidade Federal do Amazonas - \\ Manaus, Amazonas, Brasil. \\ 2Departamento de Ambiente e Ordenamento, Universidade de Aveiro - \\ Aveiro, Portugal. \\ E-mails: helder.relvas@ua.pt (HR); geisegoes@gmail.com (GC); \\ pinheiro.heitor@gmail.com (HP); awaichman@gmail.com (AW); myr@ua.pt (ML). \\ *E-mail para correspondência: jurandir.dutra@gmail.com (JD)
}

Recebido (Received): 04/11/2018

\begin{abstract}
Resumo: O Plano de Mobilidade Urbana (PlanMob) como instrumento de efetivação da Política Nacional de Mobilidade Urbana foi promulgado na Lei Federal $n^{\circ} 12.587$ de 2012. Esse marco regulatório instituí aos municípios com mais de 20 mil habitantes a obrigação da elaboração e apresentação do PlanMob até abril/2018, como condição para aptidão de investimentos de recursos federais ao município. De acordo com a lei, o PlanMob deverá estar integrado ao Plano Diretor Municipal e conter objetivos para alavancar a mobilidade não-motorizada e os modos coletivos de transporte. Em Manaus, o PlanMob foi publicado por meio da Lei municipal 2074 de 2015, o qual assinala dois cenários de intervenção, porém apresenta inconsistências nas proposições, no que tange à redução das emissões, em função de tratar em conjunto gases de efeito estufa e local, cujas tendências comportamentais são antagônicas. Tais proposições, além de não separar gases e poluentes, demonstra o melhor cenário de redução das emissões para o transporte individual, entretanto, não elenca estratégias para a redução de congestionamentos nas vias. Além disso, no último ano horizonte (2035) a redução das emissões apontada é da ordem de 3\%, mantendo acirrada a competição com o modal coletivo. Para elaborar comparativo foram estimadas as emissões do sistema de transportes de Manaus tomando como referência a abordagem bottom-up (IPCC, 2006) para os anos de 2010 a 2016. Os resultados apontam que as estimativas apresentam viés no comportamento das séries em comparação às previsões contidas no PlanMob para os mesmos anos e para as projeções do ano-horizonte de 2035. Enquanto as estimativas apresentam crescimento continuado nas emissões de $\mathrm{CO}_{2}$, o PlanMob projeta sua redução, inclusive no cenário de referência, quando nenhuma intervenção deve ocorrer nos eixos viários e no sistema de transportes públicos.
\end{abstract}

Palavras-Chave: Emissões Veiculares; Legislação Urbana; Planejamento Urbano.

Abstract: The Urban Mobility Plan (PlanMob) as an instrument for implementing the National Urban Mobility Policy (PNMU) was promulgated in 2012 (Federal Law No. 122.587). This regulatory framework established for municipalities with more than 20 thousand inhabitants the obligation to prepare and submit the PlanMob until April of 2018, as a condition to apply for Federal funds. According to the law, PlanMob must be integrated into the Municipal Master Plan and contain objectives to increase Eco-friendly mobility including public transport systems. In Manaus, the PlanMob was published by means of the Municipal Law 2074 of 2015, which points out two intervention scenarios, but presents inconsistencies in the proposals, regarding the reduction of emissions, due to the joint treatment of gases of greenhouse and local effects, whose behavioral tendencies are antagonistic. Such proposals, besides not separating greenhouse gases and 
other pollutants, presented the best scenario of emission reduction for individual transport without making reference to strategies for the reduction of road traffic congestion. In addition, in the horizon 2035 the reduction of emissions pointed out is of the order of 3\%, maintaining the competition with the public transportation systems. To make the comparison, emissions from the Manaus transport system were estimated using the bottom-up approach (IPCC, 2006) for the period between 2010 and 2016. The results show that the estimates show a bias in the performance of the series compared to the forecasts contained in PlanMob for the same years and for the projected year (2035). While the estimates show continued growth in CO2 emissions, PlanMob projects its reduction, including in the reference scenario, when no intervention should occur in the road network and in the public transport system.

Keywords: Road Emissions; Urban Legislation; Urban Planning.

\section{Introdução}

O setor energético é um dos maiores emissores de gases de efeito estufa (GEE) em face do elevado uso de combustíveis fósseis em sua matriz geradora, seja pela forte presença de modais rodoviários ou pela utilização de termelétricas. Contudo, os modais de transportes têm significante responsabilidade sobre as emissões, devido ao incremento de veículos ocorrido nas últimas décadas e à política de incentivo ao crédito automobilístico individual (DETRAN, 2016).

Os diversos modais de transporte - cargas e passageiros - apresentam grandes variações no consumo e uso de energia, diferentes emissões de gases de efeito estufa e poluentes atmosféricos. Essa energia usada no setor de transportes está diretamente associada aos transportes de passageiros e de cargas. Os combustíveis derivados de petróleo chegam a representar $97 \%$ do total de energia consumida no setor de transportes (MOTA et al., 2013). Contudo, iniciativas que contemplam biocombustíveis ou tecnologias menos poluentes têm sido implantadas nas mais diversas cidades do mundo. A partir de 1975 iniciou-se, no Brasil, a mistura de álcool etílico anidro na gasolina, a fim de reduzir o uso de combustíveis fósseis, como alternativa à crise do petróleo instalada no mundo em anos anteriores.

O modal rodoviário, o mais utilizado no Brasil, é o mais intensivo em consumo, tendo representado 90,1\% da energia total consumida no setor de transportes no ano de 1999 no país (BRASIL, 2010). Os combustíveis fósseis são os principais responsáveis pela geração de energia no setor de transportes de passageiros no cenário atual, sendo que $26 \%$ das emissões de $\mathrm{CO}_{2}$ advém dos ônibus urbanos. Se nada for feito nos próximos anos, o transporte coletivo urbano e rodoviário representará $33 \%$ das emissões desse gás (BRASIL, 2013).

Em Manaus, as emissões de $\mathrm{CO}_{2}$ do transporte público equivalem, em média, à $13 \%$ das emissões dos veículos do ciclo diesel, embora as emissões per capita tenham diminuindo levemente. Esses percentuais vêm sendo mantidos devido aos baixos investimentos na infraestrutura viária e na frota, assim como na concepção errônea de estruturação da rede. O planejamento não adota modais de média e alta capacidade de transportes que sejam menos intensivos em carbono. Desta forma, a retração observada na frota de ônibus, na quilometragem e no volume de passageiros transportados, sobretudo, a partir de 2012, sedimenta a ineficiência do sistema, incapaz de promover competição com o modal individual (DUTRA, et al, 2017).

O objetivo desta pesquisa foi estimar a dinâmica e a evolução das emissões de GEE oriundas dos transportes coletivos na cidade de Manaus. Ainda, objetivou-se dar aporte para fundamentar políticas públicas com medidas mitigadoras locais no sentido de diminuir as emissões dos gases nocivos, corroborando para minimizar os efeitos das mudanças climáticas em relação aos impactos na qualidade de vida da população.

\section{Materiais e Métodos}

\section{1. Área da Pesquisa}

A área de estudo compreende a cidade de Manaus, capital do estado do Amazonas, Brasil. Está localizada à margem esquerda do Rio Negro, na sua confluência com o Rio Solimões formando o Rio Amazonas (Figura 1). A população estimada de 2.130 .264 habitantes, área de $11.401,092 \mathrm{~km}^{2}$ e densidade demográfica de aproximadamente $186,8 \mathrm{hab} / \mathrm{km}^{2}$ (IBGE, 2017). 


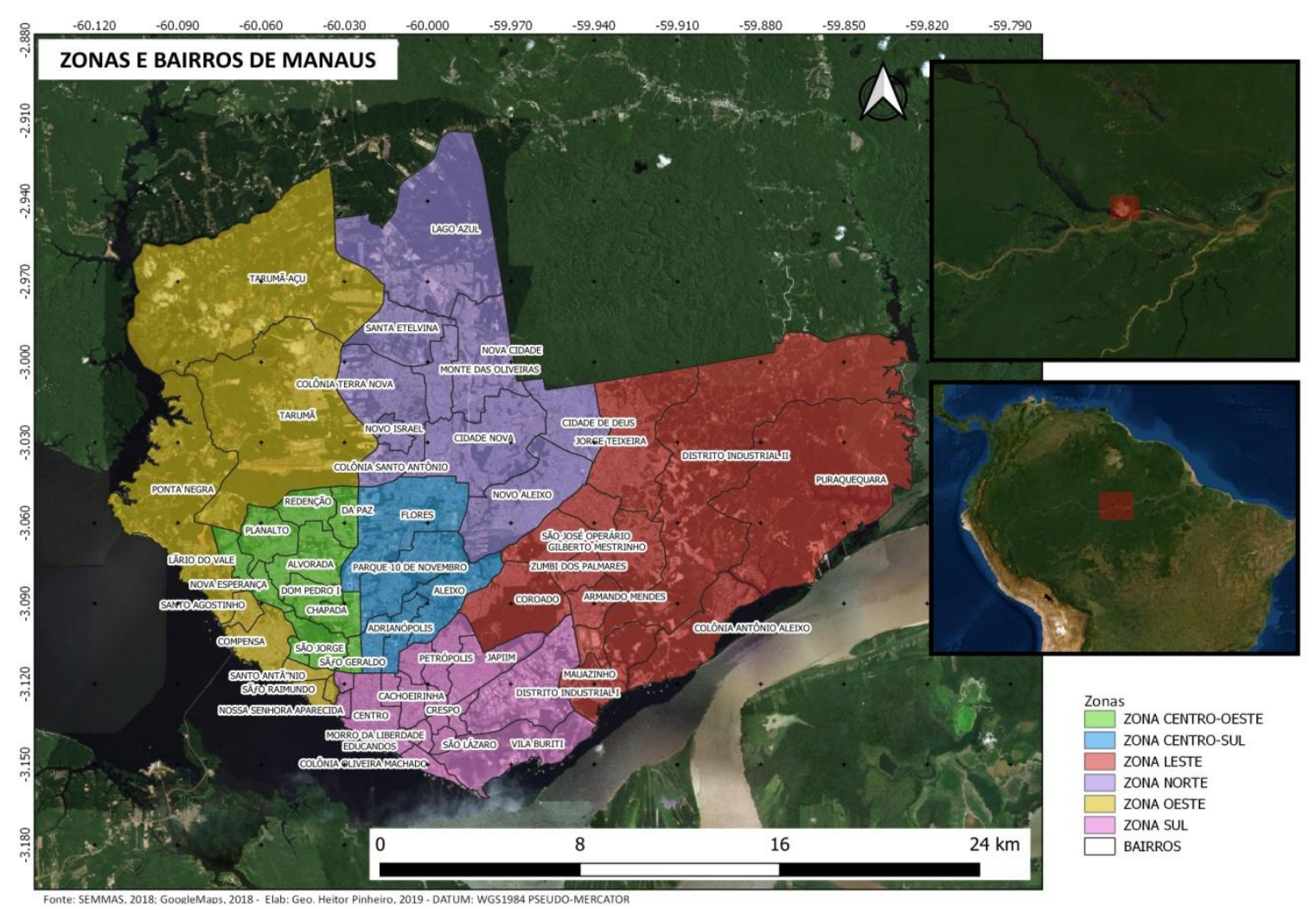

Figura 1: Mapa político da área de estudo, a cidade de Manaus-AM.

\subsection{Evolução Urbana de Manaus}

As cidades amazônicas surgiram para satisfazer a necessidade colonialista. A Coroa portuguesa precisava ocupar a região a oeste de Tordesilhas enquanto imperava a união com a coroa hispânica, para que no momento da cisão política entre as monarquias sua posse fosse considerada efetiva sobre este território. Evidentemente que, como se tratava de uma região densamente florestada, o obstáculo natural expressava uma barreira à ocupação, sendo que a estratégia ocupacional consistiu em fundar núcleos urbanos às margens dos grandes rios, pois estes funcionavam como vias de acesso (BARROS, 1999).

Os primeiros centros foram ocupados, em parte, por grupos indígenas locais já descaracterizados de sua cultura original e por grupamentos de europeus, alguns dos quais em processo de miscigenação. Esse aldeamento foi agressivo e violento, vez que certos povos indígenas foram massacrados ou aprisionados para a escravidão quando coletados às margens desses grandes rios e "descidos" em direção a Belém do Grão Pará (BARROS, 1999).

Após a independência do Brasil, já no final do século XIX, a região como um todo descobriu sua vocação natural para a produção e exportação dos produtos extraídos da seringueira, sobretudo, o látex. Momentos áureos seguiram-se a esse apogeu econômico, até que os ingleses contrabandearam sementes para a Malásia, tendo encontrado campo fértil mais competitivo que o produto nativo amazônico. Entretanto, durante este período de pujança, grandes obras arquitetônicas foram construídas em Manaus e Belém, pois tais cidades funcionavam como entreposto comercial para a borracha. Sendo assim, os barões aristocráticos, detentores do poder político e econômico, viviam ávidos para adquirir hábitos do modo de vida europeu, sobretudo o parisiense (SARGES, 2000). Esse boom econômico atraiu um fluxo migratório para a região. Eram nordestinos desempregados e flagelados da seca que vinham em busca de melhores condições de vida. Quando a decadência econômica se instalou, essa mão de obra fluiu dos seringais para os centros urbanos, especialmente para a cidade de Manaus.

Em 28 de fevereiro de 1967, o governo federal criou a Zona Franca de Manaus, por meio do Decreto-lei $\mathrm{n}^{\circ}$ 288/67. O apelo à ocupação e o temor da internacionalização da Amazônia conduziram à edição do instrumento legal que consolidou o modelo de incentivos fiscais à indústria. Manaus cresceu a partir daí praticamente sem planejamento e controle urbanos. Essa política consolidou o segundo grande fluxo migratório para a cidade, agora de várias regiões do país. A cidade então ascendeu aos grandes centros urbanos: cosmopolita e pós-moderna. Tornou-se metrópole e abandonou a calha dos cursos d'água que no passado lhe serviram de artérias, instituindo uma rede de transportes urbanos rodoviários. 
Logo após a edição do Decreto-lei ${ }^{\circ}$ 288/67, o município contou com um Plano Diretor que buscava "disciplinar o crescimento da capital amazonense por vários decênios, criando uma cidade ecológica, harmoniosa e funcional no trópico" (CORRÊA, 1969, p. 56). No entanto, este instrumento não foi eficiente porque apresentava uma série de falhas desconexas com o modelo instituído. Em seguida, foi elaborado o Plano de Desenvolvimento Local e Integrado de Manaus (PDLI) em 1970, que passou a vigorar a partir de 1975 quando foi convertido em lei como Plano Diretor. Esta proposta buscou otimizar a circulação urbana, realizando mudanças na configuração da região central da cidade. O instrumento legal não contou com participação social, tendo sido construído sob uma visão tecnicista e só foi interessante às diretrizes do capital industrial, no concernente às questões viárias e a desconcentração urbana (OLIVEIRA, 2002).

Outros Planos Diretores foram sendo implementados, mas sob o mesmo enfoque, sem a efetiva participação popular, embora as audiências públicas tenham ocorrido. A partir da década de 2000, Manaus experimentou um crescimento verticalizado. Em 2014, após revisão de certos parâmetros arquitetônicos e outras mudanças, um novo Plano Diretor foi editado permeado da mesma ideologia de seus antecessores.

\subsection{O Plano Municipal de Mobilidade Urbana - PlanMob}

A lei ordinária 2.075 de 29/12/2015 instituiu o Plano de Mobilidade Urbana de Manaus (PlanMob) em cumprimento às previsões contidas na Política Nacional de Mobilidade Urbana (PNMU). Essa lei, além de instituir o PlanMob, estabeleceu diretrizes para sua implementação, acompanhamento, monitoramento, avaliação e revisão periódica de suas proposições. Mas, também definiu os objetivos estratégicos, programas e instrumentos de gestão necessários à sua execução.

O PlanMob faz um breve relato histórico da evolução urbana da cidade e do sistema viário, depois caracteriza o transporte público, detalha a infraestrutura e os modais para enfim, concluir a fase de diagnóstico. Após o diagnóstico, ele projeta variáveis socioeconômicas, avalia demandas e as viagens necessárias para satisfazer as previsões. Em seguida, avalia a mobilidade do prognóstico e dos cenários futuros. Seus resultados são obtidos a partir do modelo de simulação de redes de transporte, com suporte de software de transporte empregado (Transcad).

O PlanMob propõe um cenário de intervenção tanto no sistema viário, com a abertura de novas vias, assim como a complementação e a comunicação entre outras já existentes, mas também a reestruturação do transporte coletivo, inclusive com a implantação de novos equipamentos urbanos e terminais de integração.

$\mathrm{Na}$ primeira parte, a proposta emerge com uma reconfiguração da malha viária, capaz de atender a demanda e criar novas necessidades de deslocamentos, de maneira a atender também às diretrizes e aos objetivos específicos contidos no Plano Diretor Urbano e Ambiental de Manaus, instituído pela Lei Complementar 002 de 16/01/2014 em seus incisos I e II do artigo 18 e inciso VII do artigo 62. A título de balanço propõe a construção de 133,42 km de intervenções em novas vias e 147,68 km em vias já existentes, perfazendo uma extensão total de $281,1 \mathrm{~km}$. Contudo, nesta proposta também há diretrizes para a recuperação de calçadas e para a implantação da malha cicloviária, idealizando a construção de $190 \mathrm{~km}$ de ciclo faixas.

Na segunda parte o PlanMob propõe mudanças estruturais baseadas na concepção do Plano Operacional para o Transporte Coletivo de Manaus, elaborado em 2011 pela Superintendência Municipal de Transporte Urbanos (SMTU), mas afirma atualizá-lo em vias das modificações da rede de transporte coletivo que ocorreram neste período. Porém, para ser sustentável o plano deve contemplar redução de congestionamentos, objetivar a mobilidade não motorizada, diminuir acidentes e as emissões (MACHADO \& PICCININI, 2018).

A intervenção está basicamente pautada na implantação de corredores do Bus Rapid Transit (BRT) ou Transporte Rápido por Ônibus, dos corredores preferenciais e dos novos equipamentos de integração. BRT é "um sistema de transporte coletivo de passageiros que proporciona mobilidade urbana rápida, confortável, segura e eficiente por meio de infraestrutura segregada com prioridade de ultrapassagem, operação rápida e frequente" (PLANMOB, 2015, p. 194).

O eixo BRT norte-sul contará com uma extensão de $30 \mathrm{~km}$ e o eixo leste-centro de 19,6 km, perfazendo um total de 49,6 km. Os corredores preferenciais somarão 39,7 km e serão segregados de vias já existentes, mas não indica se novas faixas carroçáveis serão construídas. Assim a rede de eixos estruturais totalizará 89,3 km, que de acordo com o PlanMob, garantirá a operação do transporte com qualidade e eficiência.

No que tange aos novos equipamentos de integração, o PlanMob propõe a construção de cinco novos terminais de integração e cinco estações de conexão do BRT, totalizando 10 terminais de integração 
distribuídos estrategicamente pela cidade, com o objetivo de reduzir o carregamento de linhas de ônibus para a região central da cidade. Entretanto, vale ressaltar que Manaus conta com o sistema de bilhetagem eletrônica implantado desde 2007. Esse sistema permite a integração temporal. Assim, o usuário portador do cartão inteligente, estudante ou não, pode realizar a integração com outra linha dentro de um determinado tempo-limite. Essa tecnologia reduz os deslocamentos negativos.

Provavelmente, a abertura dos terminais de integração existentes, assim como a não construção dos novos equipamentos de integração propostos no PlanMob, em consonância com a universalização da bilhetagem eletrônica reduziriam as emissões de gases de efeito estufa e local, uma vez que, diminuiriam os deslocamentos negativos e a demanda de viagens para certos pontos. Porém, seria necessário refazer o planejamento de transporte no que concerne à frota e à frequência projetadas para certas linhas. Reduzir as emissões deveria ser um dos objetivos estruturais do plano conforme apontam Machado e Piccinini (2018).

\subsection{Levantamento de Dados}

Foram realizados inventários de emissões de gases de efeito estufa oriundos da mobilidade urbana estimados com base na abordagem Bottom-up recomendada pelo Intergovernmental Panel on Climate Change (IPCC, 2006). A fronteira do inventário foi definida como o volume de combustíveis comercializados dentro do perímetro urbano da cidade, já que Manaus está isolada de outros centros urbanos. Esse método foi adotado por ser mais abrangente e requerer detalhamento de composição da frota, distância média percorrida por tipo de veículo, os fatores de emissão, assim como as tecnologias de controle de emissão. Esta abordagem deve ser preferida sempre que houver dados e informações disponíveis (IPCC, 2006).

Os volumes anuais de gasolina automotiva, etanol hidratado e óleo diesel comercializados na cidade de Manaus para o período de 2010 a 2015 foram obtidos da Agência Nacional do Petróleo - ANP (ANP, 2016). Para completar a série, o volume do consumo destes combustíveis para o ano de 2016 foi estimado através de técnica estatística de regressão simples, já que o parágrafo $2^{\circ}$ do art. $5^{\circ}$ do Decreto $\mathrm{n}^{\circ} 7724 / 12$ impede a divulgação da venda de combustíveis, por município, antes de decorridos 12 meses do exercício.

Com o intuito de partilhar as emissões do transporte público urbano de passageiros por ônibus foram coletados junto a Superintendência Municipal de Transportes Coletivos - (SMTU) a composição da frota, assim como a quilometragem percorrida para o período de 2010 a 2016 e o consumo de biodiesel para o ano de 2009 (SMTU, 2016). Desta forma, a estimativa de combustível para os demais anos da série foi obtida por proporcionalidade e uso de regra de três composta.

A composição da frota total estratificada por categoria de veículos para o período de 2010 a 2016 foi obtida junto ao Departamento Estadual de Trânsito - DETRAN/AM. Contudo, esta estratificação não fazia referência à matriz energética, em suas composições dos ciclos termodinâmicos de motores, conforme configuração adotada no $1^{\circ}$ Inventário Nacional de Emissões Atmosféricas por Veículos Automotores Rodoviários (BRASIL, 2011). Apenas classificava por tipo de veículos (micro-ônibus, automóveis, caminhão, motocicleta, ônibus etc.). Assim, a fim de acompanhar as recomendações exaradas pelo documento em questão, a frota foi distribuída por ciclos (otto e diesel), sendo, para tal, estratificada nas mesmas proporções da composição da frota nacional (Tabela 1). Com isto, a construção de políticas públicas pode ser direcionada para avaliar a tecnologia dos motores e para a gestão da fonte energética.

\subsection{Metodologia}

O presente estudo foi desenvolvido utilizando métodos protocolares matemáticos e estatísticos. Para isso foi realizado o inventário das emissões veiculares do sistema de transportes, considerando basicamente a abordagem Bottom-up (IPCC, 2006) e adequações sugeridas pelo governo brasileiro e/ou extraídas de iniciativas e experiências de outras cidades brasileiras, como Belo Horizonte e Rio de Janeiro, sobretudo, na definição das fronteiras do inventário. Foram inventariadas emissões de dióxido de carbono - $\mathrm{CO}_{2}$ e metano $-\mathrm{CH}_{4}$, com o objetivo de compor o $\mathrm{CO}_{2 \mathrm{e}}$.

Neste trabalho não foram estimadas as emissões veiculares oriundas do gás natural veicular - GNV, em face da ausência de dados associado ao fato dessa matriz ter sido disponibilizada há apenas quatro anos e segundo a literatura representa somente $2 \%$ frota brasileira (BRASIL, 2011). 
Tabela 1. Composição da frota de veículos dos ciclos otto e diesel da cidade de Manaus - 2010 a 2016.

\begin{tabular}{|c|c|c|c|c|c|c|c|c|c|}
\hline Ciclo & Categoria & Combustível & 2010 & 2011 & 2012 & 2013 & 2014 & 2015 & 2016 \\
\hline \multirow{8}{*}{ 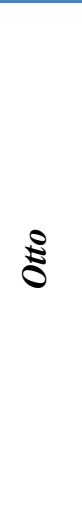 } & \multirow{3}{*}{$\stackrel{巳}{\Xi}$} & Gasolina C & 137.877 & 131.655 & 123.846 & 116.350 & 107.946 & 98.199 & 88.181 \\
\hline & & Etanol & 14.171 & 12.884 & 11.556 & 10.634 & 9.187 & 7.986 & 6.852 \\
\hline & & Flex & 119.980 & 147.996 & 175.396 & 203.873 & 230.803 & 253.367 & 271.731 \\
\hline & \multirow{3}{*}{ ֻٕ } & Gasolina C & 21.123 & 20.079 & 19.215 & 18.322 & 17.349 & 16.435 & 15.474 \\
\hline & & Etanol & 1.821 & 1.563 & 1.344 & 1.146 & 965 & 809 & 670 \\
\hline & & Flex & 16.459 & 19.298 & 22.075 & 24.549 & 26.568 & 28.276 & 29.456 \\
\hline & \multirow{2}{*}{$\stackrel{\stackrel{0}{0}}{e^{\circ}}$} & Gasolina C & 96.889 & 108.768 & 120.727 & 132.881 & 148.775 & 158.594 & 165.886 \\
\hline & & Flex & 3.281 & 5.116 & 7.045 & 9.058 & 11.418 & 13.353 & 15.038 \\
\hline \multicolumn{2}{|c|}{ Total Otto } & & 411.601 & 447.359 & 481.204 & 516.813 & 553.011 & 577.019 & 593.288 \\
\hline \multirow{4}{*}{ 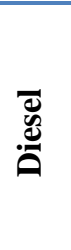 } & Leves & Biodiesel & 40.679 & 47.298 & 51.859 & 56.254 & 60.965 & 64.378 & 65.818 \\
\hline & Pesados & Biodiesel & 33.567 & 34.459 & 36.727 & 38.981 & 38.564 & 38.940 & 39.175 \\
\hline & T. Público & Biodiesel & 1.295 & 1.292 & 1.502 & 1.478 & 1.414 & 1.410 & 1.362 \\
\hline & Ônibus & Biodiesel & 9.677 & 10.921 & 11.688 & 12.166 & 12.471 & 12.388 & 12.305 \\
\hline \multicolumn{2}{|c|}{ Total Diesel } & & 85.218 & 93.970 & 101.776 & 108.879 & 113.414 & 117.116 & 118.660 \\
\hline \multicolumn{3}{|c|}{ Total anual } & 496.819 & 541.329 & $\mathbf{5 8 2 . 9 8 0}$ & 625.692 & 666.425 & 694.135 & 711.948 \\
\hline
\end{tabular}

Fonte: DETRAN-AM (2016) e BRASIL (2011) com adaptações.

\subsubsection{Abordagem Bottom-up}

Esse método foi adotado para o cálculo do $\mathrm{CO}_{2}$ e $\mathrm{CH}_{4}$ no período compreendido entre 2010 e 2016 porque esta metodologia, por ser mais abrangente, requer detalhes como a composição da frota estratificada, distância média percorrida por tipo de veículo, os fatores de emissão específicos declarados pelo fabricante ou adotados com base no Programa de Controle de Poluição do Ar por Veículos Automotores - PROCONVE ou pelo Programa de Controle da Poluição do Ar por Motocicletas e Veículos Similares - PROMOT, assim como as tecnologias de controle de emissão.

As dificuldades encontradas estão referendadas no $1^{\circ}$ Inventário de Emissões Atmosféricas por Veículos Automotores Rodoviários publicado em 2011 pelo governo brasileiro. Adotou-se, neste documento oficial, que o procedimento de inventário dos poluentes atmosféricos foi categorizado por tipo/modelo de veículos, matriz energética, fatores de emissão e tecnologia do motor.

\subsubsection{Equação Geral}

As emissões são estimadas, para cada ano, adotando-se a seguinte fórmula:

$$
\text { E }=\text { Fr x Iu x Fe }
$$

onde:

$\mathbf{E}=$ taxa anual de emissão do poluente considerado (g/ano);

$\mathbf{F r}=$ Frota circulante do ano modelo considerado (número de veículos);

$\mathbf{I} \mathbf{u}=$ Intensidade de uso do modelo considerado $(\mathrm{km} / \mathrm{ano})$;

$\mathbf{F e}=$ Fator de emissão do poluente considerado $\left(\mathrm{g}_{\text {poluente }} / \mathrm{km}\right)$

\subsection{Frota Circulante}

A frota circulante proposta pelo $1^{\circ}$ Inventário Nacional de Poluentes Atmosféricos por Veículos Automotores Rodoviários foi classificada em veículos do ciclo otto e do ciclo diesel, sendo estratificada por tipo de combustível adotado (BRASIL, 2011). O ciclo otto é um ciclo termodinâmico, em quatro tempos, 
que idealiza a combustão interna de motores a partir da ignição por centelha. Foi anteriormente definido por Beau de Rochas e posteriormente implementado por Nikolas Otto, em 1876, tendo o seu nome batizado o ciclo. A maioria dos carros de passeio são equipados com motores do ciclo otto.

Os veículos do ciclo otto foram subclassificados em: automóveis, comerciais leves e motocicletas, movidos a gasolina automotiva e/ou etanol hidratado. Os veículos do ciclo diesel foram subclassificados em: comerciais leves, ônibus urbanos, ônibus rodoviários, caminhões leves, caminhões médios e caminhões pesados tendo como matriz energética o biodiesel.

Como, no caso de Manaus, a estratificação não considerava o combustível, utilizou-se a mesma proporção nacional para a composição da frota local, sendo que os caminhões leves, caminhões médios e caminhões pesados foram classificados todos como "Outros Pesados", assim como os ônibus rodoviários e os ônibus urbanos foram classificados todos como "Ônibus", uma vez que na base de dados fornecida pelo DETRANAM não havia esta separação (Tabela 1). Entretanto, as emissões dos ônibus do transporte coletivo público urbano foram partilhadas das demais.

\subsection{Intensidade de Uso}

É uma variável dependente de vários fatores socioeconômicos, mas no $1^{\circ}$ Inventário Nacional de Poluentes Atmosféricos por Veículos Automotores Rodoviários representa a idade do veículo.

Devido à escassez de dados e à pequena representatividade nos estudos encontrados, a intensidade de uso foi estabelecida a partir do consumo de combustível rodoviário observado no país e declarado no Balanço Energético Nacional (BEN) - 2010 (BRASIL, 2010; 2011). Com base na quilometragem por litro (km/l) e na intensidade de uso de referência ( $\mathrm{km} / \mathrm{ano}$ ) estima-se o consumo de combustível de cada categoria de veículos do ciclo otto e do ciclo diesel.

\subsection{Fatores de Emissão}

O IPCC recomenda que sempre que houver fator de emissão local ou regional disponível, este deve ser preferido em detrimento a qualquer outro. No entanto, essas informações, se existem, não estão disponíveis. Dessa forma, adotaram-se os mesmos fatores de emissão, para cada gás, definido no $1^{\circ}$ Inventário Nacional de Poluentes Atmosféricos por Veículos Automotores Rodoviários.

Estes fatores foram estabelecidos com base nos fatores médio de emissão dos poluentes regulamentados pelo PROCONVE e PROMOT, disponibilizados pela CETESB em seus relatórios de qualidade do ar e apontam para fatores mais próximos da realidade brasileira (VIANNA et al., 2009; BRASIL, 2011).

\section{Resultados e Discussão}

\subsection{Emissões de Dióxido de Carbono - $\mathrm{CO}_{2}$}

As emissões de $\mathrm{CO}_{2}$ inventariadas a partir da abordagem Bottom-up para o período de 2010 a 2016 apresentaram valores com tendência linear de baixa amplitude para todos os combustíveis, com leve inclinação no final da série para o diesel e o etanol hidratado (Figura 2). O aumento substancial da frota de veículos pesados contribuiu sensivelmente para a elevação do diesel, enquanto a evolução dos fuel flex na composição da frota de veículos do ciclo otto foi substancial para o para o salto do etanol hidratado (Figura 2).

A série de gasolina A (gasolina pura) inicia com números da ordem de 496,2 mil tC e finda com valores de 531,2 mil tC, equivalendo a um crescimento de, aproximadamente, 7\%. Da mesma forma, a série de etanol anidro apresenta o mesmo comportamento. Os valores iniciais, em 2010, estão na casa de 89,9 mil tC e vão crescendo até atingir 96,2 mil tC emitidas em 2016. A mistura destes dois combustíveis (gasolina pura e etanol anidro) compõem a gasolina $\mathrm{C}$ distribuída nos postos de venda de combustíveis. Contudo, os veículos do ciclo otto movidos a gasolina $\mathrm{C}$ e etanol hidratado têm apresentado variação negativa da frota para todos anos, a partir de 2010, em face da preferência do consumidor por motores fuel flex (Tabela 1). 


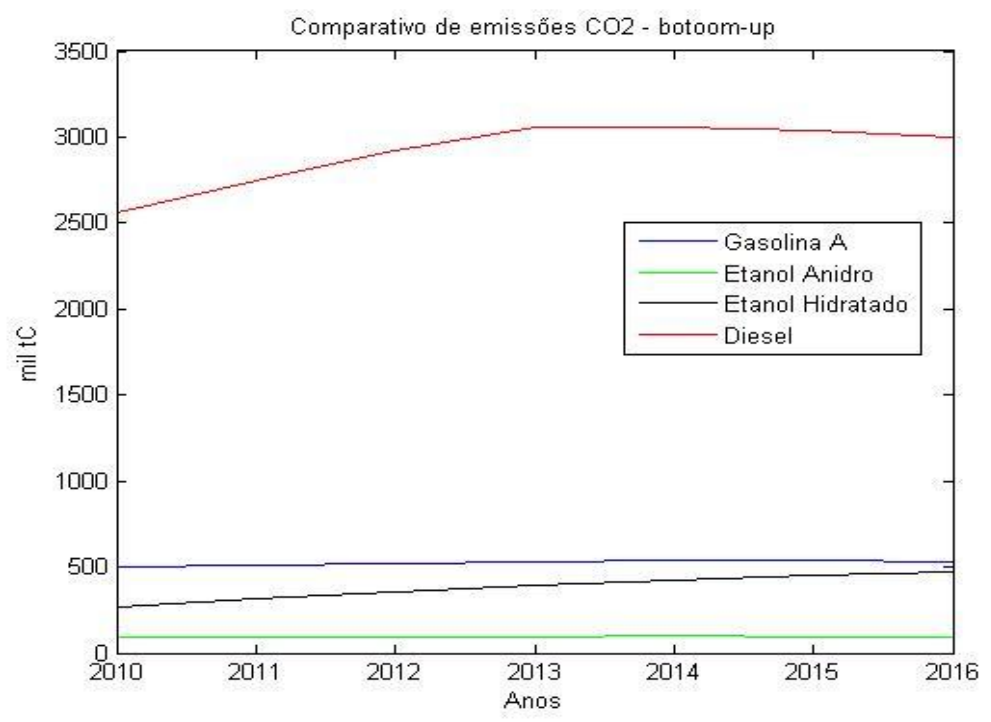

Figura 2: Emissões de $\mathrm{CO}_{2}$ na cidade de Manaus, para cada combustível, no período de 2010 a 2016. Abordagem Bottom-up com adequações.

As emissões de etanol hidratado apresentam valores de 267,2 mil tC em 2010, atingem 393,1 mil tC em 2013 e praticamente dobram em 2016 em relação ao ano inicial de contabilização (468,4 mil tC). O diesel inicia a série emitindo 2.564,1 mil tC e apresenta crescimento para o período analisado. Em 2013 apresenta emissão máxima (3.061,8 mil tC) e em seguida exibe decrescimento sutil contribuindo com 3.002,4 mil tC em 2016, mesmo representando um crescimento acumulado de 7\% em relação ao ano de referência - 2010 (Figura 2), Este decrescimento observado nas emissões do diesel pode ser creditado provavelmente à estagnação da frota de transporte público (SMTU, 2016) e a adoção do gás natural proveniente da bacia do rio Urucu a partir de 2012 como matriz na geração de energia elétrica do sistema (ELETROBRAS, 2016).

Ao avaliar as emissões por categoria da frota, observou-se crescimento nas emissões dos veículos do ciclo otto em todos os estratos. Os automóveis iniciam a série com emissões de 704,8 mil tC em 2010 e chegam a 906,3 mil tC em 2016, representando incremento de cerca de $30 \%$.

Os automóveis comerciais leves apresentam menores amplitudes com acréscimo de $9 \%$ no período 20102106, 102,8 mil tC e 112 mil tC, respectivamente. As motocicletas, entre todas as categorias, têm o crescimento mais expressivo de emissões do ciclo registrando valores da ordem de 45,6 mil tC em 2010 e 77,2 mil tC em 2016, acréscimo de aproximadamente 70\% (Figura 3).

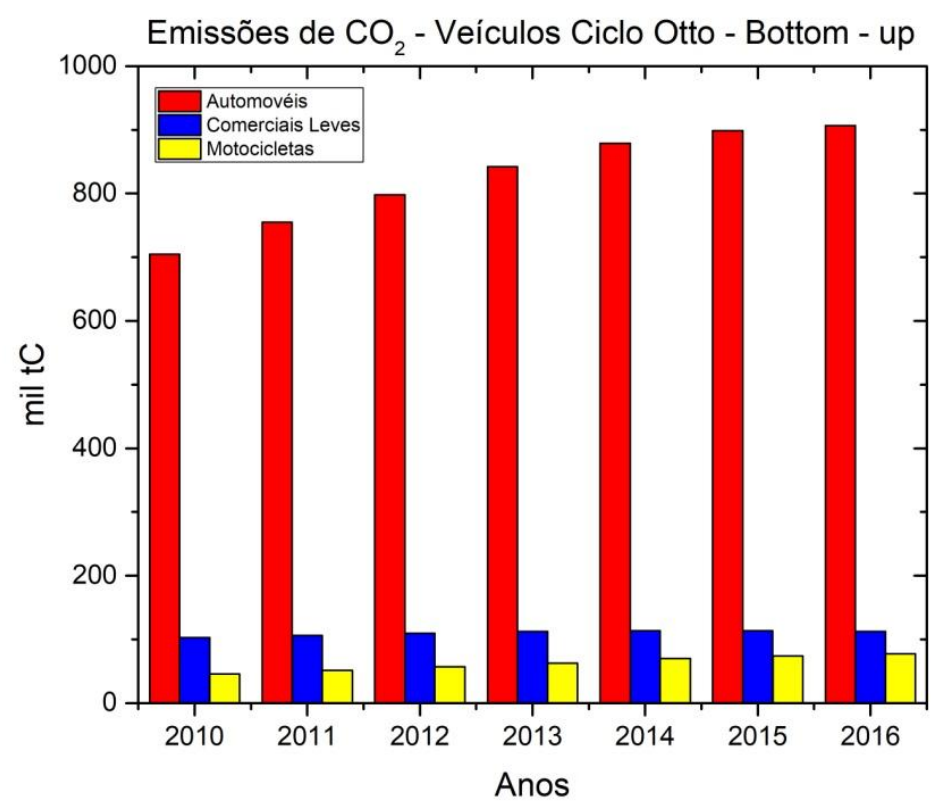

Figura 3: Emissões de $\mathrm{CO}_{2}$ na cidade de Manaus para os veículos do ciclo otto no período de 2010 a 2016. Abordagem Bottom-up com adequações. 
Esse comportamento observado é resultado das políticas públicas de incentivo ao crédito implementadas a partir do final da década de 1990, que ocasionaram competição acirrada do modal individual com o coletivo (DUTRA et al., 2017).

As emissões dos veículos do ciclo diesel registraram acréscimos significativos, com exceção dos ônibus do transporte público coletivo de passageiros, cujas emissões comportaram-se de maneira tendendo a linearidade (Figura 4). Esse comportamento é resultado de anos de baixos investimentos no setor. A frota e a quilometragem diminuíram na última década, reduzindo a qualidade do serviço (SMTU, 2016).

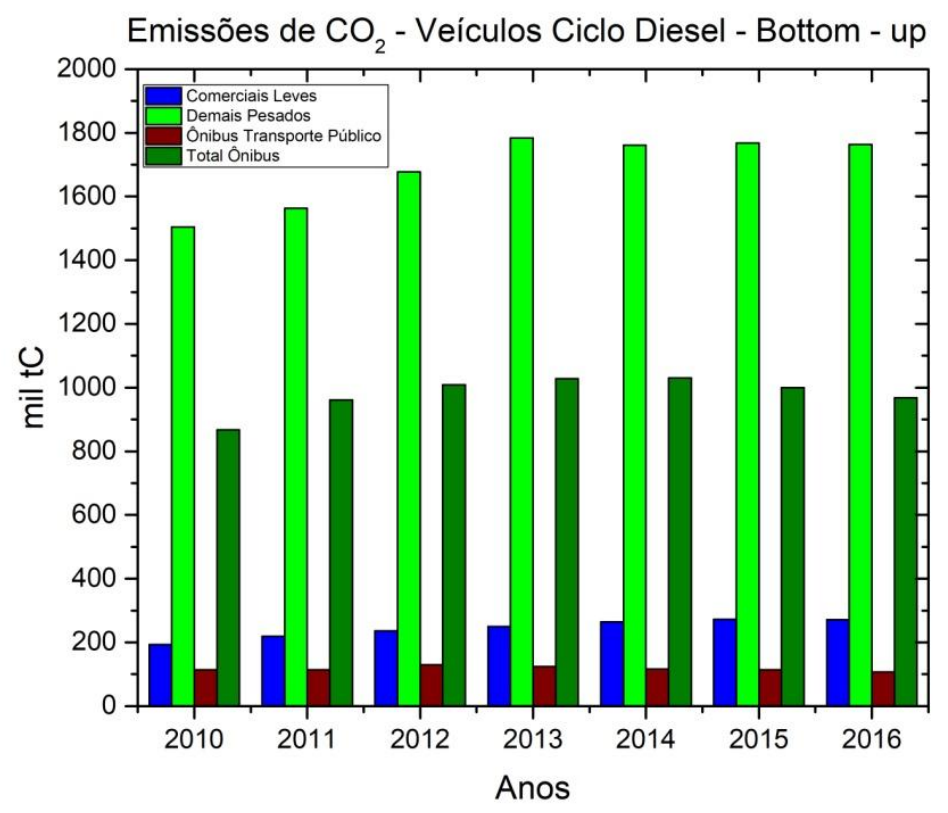

Figura 4: Emissões de $\mathrm{CO}_{2}$ na cidade de Manaus para os veículos do Ciclo Diesel no período de 2010 a 2016. Abordagem Bottom-up com adequações.

A competição acirrada promovida pelo transporte individual, cuja frota de veículos cresceu em ritmo acelerado por meio dos incentivos ao crédito, agregada à popularização dos carros fuel flex e à acentuada crise político-econômica que se instalou no Brasil a partir de 2014 (DUTRA, et al., 2017) podem ser fatores determinantes para esse quadro. Contudo, os percentuais de acréscimos nas emissões finais em 2016, para todos os estratos analisados, não contabilizaram incrementos como os dos veículos do ciclo otto (Figura 4).

Os automóveis comerciais leves do ciclo diesel emitiram 192,7 mil tC em 2010 e 271,6 em 2016. Esta categoria apresentou crescimento em torno de $40 \%$ e foi a mais expressiva de todas deste ciclo. As emissões dos veículos pesados contabilizaram 1.503,9 mil tC em 2010 e cresceram até a casa de 1.762,8 mil tC em 2016.

Para os ônibus a série inicia-se com valores da ordem de 867,5 mil tC e atingem o ápice das emissões em 2014, com 1030 mil tC para em seguida decrescer, fechando a série com 968 mil tC em 2016. Os ônibus do transporte coletivo público de passageiros emitiram 113,6 tC em 2010 e mantêm o comportamento até o final do período analisado, observando uma redução da ordem de 5\% para o ano de 2016 (107,4 mil tC) (Figura 4).

A curva do crescimento das emissões observadas nos resultados obtidos pela abordagem Bottom-up parece coerente com a função expressa na evolução da frota de veículos que cresceu exponencialmente entre 2010 e 2016 atingindo a ordem de 711.948 veículos (Tabela 1).

\subsection{Emissões de Metano - $\mathrm{CH}_{4}$}

As emissões de $\mathrm{CH}_{4}$ foram inventariadas apenas para os veículos do ciclo otto, uma vez que o "1" Inventário Nacional de Emissões Atmosféricas por Veículos Automotores Rodoviários" não traz orientações, dados ou informações acerca das emissões do ciclo diesel. Esse gás, embora seja um hidrocarboneto e possível catalisador de formação de $\mathrm{O}_{3}$ troposférico, funciona muito mais como gás de efeito estufa, cujo potencial de aquecimento é 21 vezes superior ao potencial do $\mathrm{CO}_{2}$ (IPCC, 2006) 
Observaram-se que as emissões de $\mathrm{CH}_{4}$ oriundas da gasolina $\mathrm{C}$ vêm decrescendo a cada ano, ainda que a frota de veículos evolua em sentido contrário. Entretanto, as emissões originadas a partir do etanol mantêmse estáveis. Os volumes totais de emissão decrescem de 275 t/ano em 2010 para 186,3 t/ano em 2016 verificando uma eficiência de quase 7\%, o que representa um decrescimento médio anual de 1\% (Figura 5).

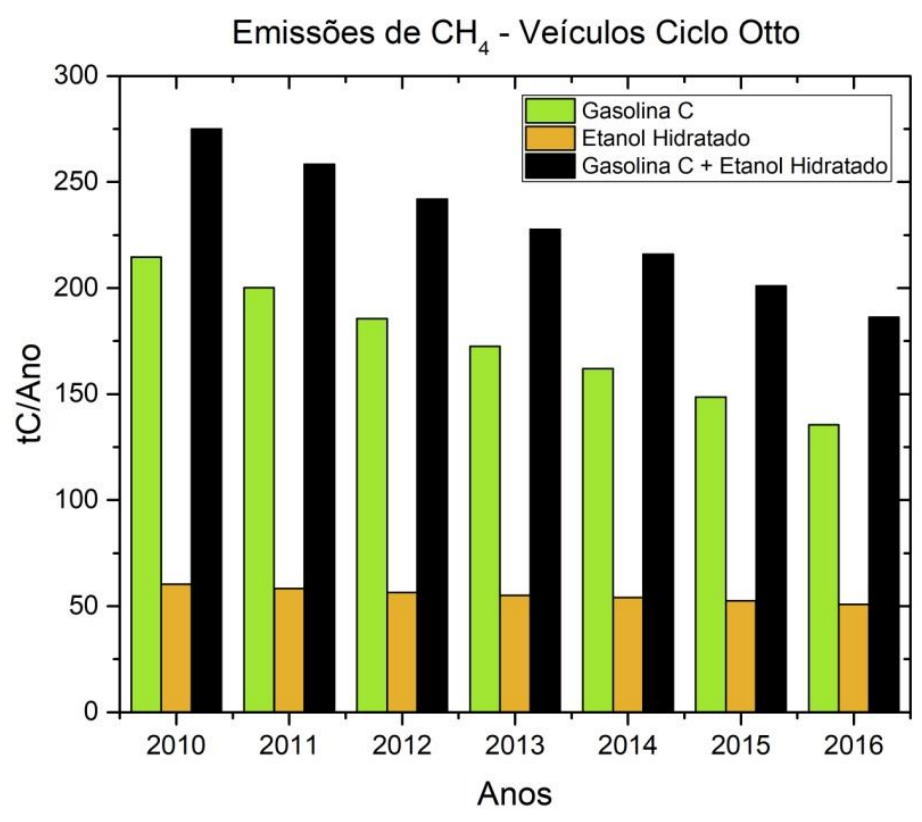

Figura 5: Emissões de $\mathrm{CH}_{4}$ na cidade de Manaus de veículos do ciclo otto, por tipo de combustível, no período de 2010 a 2016. Abordagem Bottom-up com adequações.

Esse comportamento registrado na série de gasolina $\mathrm{C}$ pode ser justificado pela mistura de etanol anidro em sua composição e pela evolução das tecnologias dos motores que reduziram as emissões de hidrocarbonetos totais - THC, entre eles o $\mathrm{CH}_{4}$, mas também devido à evolução tecnológica obtida a partir da implantação de fases mais avançadas do PROCONVE/PROMOT (BRASIL, 2011).

A estabilidade das emissões de etanol pode ser justificada em vistas à sazonalidade do biocombustível, quando em períodos de entressafra os custos sobem e são repassados ao consumidor ou carecem de políticas públicas de incentivo ao setor sucroalcooleiro. Esses entraves reduzem a adesão ocasional a essa matriz, ainda que a frota de veículos fuel flex esteja dominando o mercado.

Quando analisadas as emissões por categorias de veículos do ciclo otto, independentemente do combustível adotado (Tabela 2) e a evolução dos automóveis e motocicletas (Tabela 1), percebe-se que o decrescimento nas emissões confirma a tese de que a evolução da tecnologia de motores vem reduzindo as emissões deste gás. É evidente a redução ser mais sutil para as motocicletas e mais intensa para os comerciais leves, isto porque os veículos desta última categoria apresentam crescimento da frota de aproximadamente $16 \%$, enquanto as motocicletas registram cerca de $81 \%$ de incremento em seu parque.

Os automóveis registram redução das emissões da ordem de 35\%, decrescendo de 161,7 t/ano em 2010 para 104,3 t/ano em 2016. Os comerciais leves emitiram em 2010 22,3 t/ano e em 2016, 12,1 t/ano, representando redução em torno de 46\% (Tabela 2). Embora em valores absolutos pareça ser mais eficiente, isso não se confirma quando comparadas as evoluções de frota de ambas as categorias (Tabela 1), devido provavelmente à implantação de fases mais rigorosas do PROCONVE/PROMOT que exigiram maior eficiência dos motores (BRASIL, 2011).

As motocicletas, cujo crescimento da frota é mais significativo (Tabela 1), registrou a menor redução de emissões. Em 2010 essa categoria emitiu 91 t/ano e fechou 2016 com 69,8 t/ano, decrescendo aproximadamente 24\% (Tabela 2). Quando avaliadas as eficiências de redução das emissões, percebe-se que as motocicletas foram as mais significativas, pois foi a categoria que registrou o maior crescimento da frota em torno de $81 \%$ - embora tenha apresentado a menor redução da emissão. Neste caso, a intensidade de uso não foi considerada, em face da linearidade observada no consumo médio de combustível das três categorias que contabilizou incremento de $48 \%$ para todas (BRASIL, 2011). 
Tabela 2: Quadro comparativo geral das estimativas de emissões de $\mathrm{CH}_{4}$ da cidade de Manaus para categorias de veículos do ciclo otto, no período de 2010 a 2016.

\begin{tabular}{|c|c|c|c|c|c|c|}
\hline \multicolumn{7}{|c|}{ Evolução das emissões de $\mathrm{CH}_{4-}(\mathrm{t} / \mathrm{ano})$} \\
\hline \multicolumn{7}{|c|}{ Veículos do Ciclo Otto } \\
\hline Anos & \multicolumn{2}{|c|}{ Automóveis } & & n. Leves & & ocicletas \\
\hline 2010 & \multicolumn{2}{|c|}{161,7} & & 22,3 & & 91 \\
\hline 2011 & \multicolumn{2}{|c|}{151} & & 19,9 & & 87,5 \\
\hline 2012 & \multicolumn{2}{|c|}{140,2} & & 18 & & 83,8 \\
\hline 2013 & \multicolumn{2}{|c|}{131,3} & & 16,3 & & 80,2 \\
\hline 2014 & \multicolumn{2}{|c|}{122,6} & & 14,7 & & 78,8 \\
\hline 2015 & \multicolumn{2}{|c|}{113,3} & & 13,3 & & 74,5 \\
\hline 2016 & 104,3 & $0,645^{*}$ & 12,1 & $0,543 *$ & 69,8 & $0,767 *$ \\
\hline
\end{tabular}

\subsection{Comparabilidade de Emissões de $\mathrm{CO}_{2 e}$}

A Tabela 3 apresenta um comparativo das emissões de $\mathrm{CO}_{2 \mathrm{e}}$ totais e per capita de sete cidades brasileiras estimadas com base na abordagem Bottom-up, com ajustes peculiares na metodologia de acordo com as limitações pontuais. Manaus surge como a segunda maior emissora $\left(2,01 \mathrm{tCO}_{2 \mathrm{e}} / \mathrm{hab} \mathrm{em} 2015\right)$, atrás apenas de Curitiba com 2,23 tCO 2 /hab em 2013.

Tabela 3: Quadro comparativo de emissões de $\mathrm{CO}_{2 \mathrm{e}}$ totais e per capita para oito capitais brasileiras em variados anos - em toneladas/ano

\begin{tabular}{|l|c|c|c|}
\hline Capitais brasileiras & $\begin{array}{c}\text { Ano do } \\
\text { Inventário }\end{array}$ & Emissões totais & Per capita \\
\hline Curitiba & 2013 & 4.125 .853 & 2,23 \\
\hline Manaus & 2015 & 4.127 .400 & 2,01 \\
\hline Recife & 2015 & 2.910 .929 & 1,80 \\
\hline Belo Horizonte & 2009 & 3.752 .739 & 1,58 \\
\hline Fortaleza & 2012 & 3.827 .521 & 1,56 \\
\hline São Paulo & 2009 & 15.111 .000 & 1,40 \\
\hline Salvador & 2013 & 3.698 .964 & 1,27 \\
\hline
\end{tabular}

Fonte: Adaptado de autores diversos

As estimativas aqui comparadas foram calculadas e reportadas entre 2009 (Belo Horizonte e São Paulo) e 2015 (Recife e Manaus) e não contemplam as regiões metropolitanas. Todas as cidades são conurbadas, com exceção de Manaus. As definições da fronteira dos inventários obedeceram a decisões de ordem políticoadministrativa (BELO HORIZONTE, 2009; SÃO PAULO, 2009; FORTALEZA, 2012; CURITIBA, 2013; SALVADOR, 2013; RECIFE, 2015).

De toda forma, os ajustes metodológicos adotados na experiência de cada cidade são pontuais e não consideram a comercialização do combustível de um território, cujas emissões ocorreram em outro do entorno e vice-versa.

Entretanto, comparar emissões cujas decisões de um inventário podem divergir de outro, atenta para o fato da ausência de um padrão protocolar ainda que suas orientações metodológicas estejam embasadas no Guia IPCC 2006 que norteia reportes nacionais. Não há de fato um guia consistente e reconhecido pela comunidade internacional que permita certa uniformidade. Todavia o Global Protocol for Community Scale Greenhouse Gas Emissions (GPC) desponta como iniciativa de várias instituições especialistas em cálculos e publicações de inventários que visa suprir esta lacuna (NEVES, 2013). 


\subsection{Mitigações propostas pelo Plano Municipal de Mobilidade Urbana}

No cenário de melhorias, com ano-horizonte definido em 2035, o PlanMob aponta um volume de redução nas emissões de gases de efeito estufa e poluentes atmosféricos da ordem de 10,9\%, considerados os modais individuais e coletivos, em relação ao cenário de não-intervenção. Contudo, embora declare a metodologia, não segrega as emissões por combustível, categoria de veículos, gás ou poluente. Assim não é possível inferir se todas as emissões estão realmente diminuindo ou se há compensações entre elas.

Neste sentido há indícios de inconsistências, pois as emissões dos gases de efeito estufa e local oriundos da mobilidade urbana de Manaus têm comportamentos diferentes. Observou que as emissões de $\mathrm{CO}_{2}$ dos automóveis vêm aumentando, desde 2010, na mesma proporção de crescimento da frota, enquanto as dos demais gases e poluentes, entre eles o metano $\left(\mathrm{CH}_{4}\right)$, vem diminuindo sensivelmente, graças à implementação de fases mais avançadas do PROCONVE e PROMOT.

Mas esse comportamento não foi observado nos ônibus do transporte público. Nesta categoria, as emissões de $\mathrm{CO}_{2}$ diminuíram consideravelmente a partir de 2010 porque os indicadores de quilometragem percorrida, passageiros transportados, assim como a frota sofreram substanciais retrações (DUTRA et al., 2017).

Por outro lado, o PlanMob prevê somente a redução de 3\% nas emissões dos gases de efeito estufa e poluentes atmosféricos no transporte individual para o ano de 2035. Isso significa dizer que em suas proposições não há convencimento suficiente para que as políticas de transporte coletivo sejam, de fato, prioritárias.

Da mesma forma, não foi contemplada nenhuma proposta de adoção de modal ferroviário urbano ou submetida ao uso de biocombustíveis e/ou energia elétrica na frota do transporte público, pois o Brasil deve aumentar sensivelmente a produção de etanol dos atuais 12 para 92 bilhões de litros em 2035, se mantidas as premissas dos cenários estabelecidos pelo IPCC (SBD, 2010).

Por fim, pode se afirmar que a metodologia de construção do PlanMob está eivada de vícios há tempos condenados. Este instrumento surge apenas para dar legitimidade a uma exigência contida na PNMU, tanto que sua edição ocorreu há três dias do prazo final estabelecido na referida lei. Embora todos os institutos de consulta popular tenham ocorrido no âmbito do poder legislativo e executivo, o PlanMob peca por ser uma grande ilusão e conter uma visão puramente tecnicista, com teatralidade de soluções incoerentes, com pouco interesse público, que além de conter ideologia alienante e alienada está envolto à hipocrisia involuntária, em consonância com as observações de Villaça (2005) e Oliveira (2002).

\section{Considerações Finais}

Foram estimadas as emissões de $\mathrm{CO}_{2}$ dos transportes rodoviários de Manaus para todos os combustíveis e categorias de veículos distribuídas por ciclos, para os anos de 2010 a 2016, adotando a abordagem Bottom-up com adequações. Da mesma forma estimou-se o $\mathrm{CH}_{4}$, mas apenas para o ciclo otto.

As emissões de $\mathrm{CO}_{2 \mathrm{e}}$ foram calculadas a fim de se estabelecer comparativo entre reportes de outras cidades brasileiras e cumprir, assim, a recomendação do IPCC de comparar contabilidades. Entretanto, devido à ausência de padrões metodológicos que orientem as definições da fronteira dos inventários e outras decisões necessárias que contemplem o uso de matrizes variadas, a comparação torna-se inadequada.

Buscou-se neste estudo dar aporte técnico-metodológico para fundamentar a construção de políticas públicas capazes de mitigar as emissões antrópicas da mobilidade urbana fundamentais para promover qualidade de vida à população, atenuando as mudanças climáticas, em nível local.

As emissões de $\mathrm{CO}_{2}$ e $\mathrm{CO}_{2 \mathrm{e}}$ crescem e acompanham o incremento da frota de veículos, em todos os ciclos e categorias, com exceção dos ônibus do transporte público, onde se observou certa linearidade creditada, sobretudo, à ineficiência, estagnação e decrescimento dos indicadores do sistema.

O PlanMob foi construído como exigência da PNMU e, portanto, apresentou pouca qualificação enquanto instrumento de planejamento urbano, uma vez que não contemplou outros modais menos intensivos em carbono e de alta capacidade, suficientes para reduzir os congestionamentos e as emissões. Da mesma forma, não elaborou estudos mais consistentes para a implementação do transporte hidroviário, embora seja um modal representativo da cultura local, com capacidade de desafogar o carregamento das vias das zonas central e adjacentes. 
As incoerências podem ser observadas, menos nas definições metodológicas, todas declaradas, mas, sobretudo, nos resultados discutidos e na ideologia de construção do instrumento incapaz de satisfazer aos seus objetivos por estar carente de participação e interesse popular.

Para solucionar a questão metodológica sugere-se acompanhar o amadurecimento das orientações para a construção de um protocolo padrão do GPC, a fim de adotá-lo. Quanto ao processo de elaboração e edição do Plano de Mobilidade Urbana, sugere-se sejam adotadas ações de empoderamento social com o intuito de despertar o interesse público ao instrumento de ordenamento urbano.

\section{Referências}

AGÊNCIA NACIONAL DO PETRÓLEO - ANP. (2016). Dados da distribuição e venda de combustíveis na cidade de Manaus para o período de 1190 a 2015. Comunicação pessoal.

BARROS, L. V. Os historiadores e os rios: natureza e ruína na Amazônia brasileira. Brasília: UnB, 1999.

BELO HORIZONTE, Prefeitura Municipal. Inventário Municipal de Emissões de Gases de Efeito Estufa. Relatório Final. 2009. Disponível em:

http://www.pbh.gov.br/smpl/PUB_P015/Relat\%C3\%B3rio+Final+Gases+Estufa. Acesso em 12 mar 2017.

BRASIL. (2010). Primeiro Inventário Brasileiro de Emissões Antrópicas de Gases de Efeito Estufa: emissões de dióxido de carbono por queima de combustíveis: abordagem Top-down. Relatórios de Referência. Ministério da Ciência e Tecnologia - MCT.

BRASIL. (2010). Primeiro Inventário Brasileiro de Emissões Antrópicas de Gases de Efeito Estufa: emissões de dióxido de carbono por queima de combustíveis: abordagem Bottom-up. Relatórios de Referência. Ministério da Ciência e Tecnologia - MCT.

BRASIL. (2010). Balanço Energético Nacional - BEN. Ministério das Minas e Energia - MME.

BRASIL. (2011). Primeiro Inventário Nacional de Emissões Atmosféricas por Veículos Automotores Rodoviários. Ministério do Meio Ambiente - MMA.

BRASIL. (2013). Plano Setorial de Transporte e Mobilidade Urbana para Mitigação da Mudança do Clima - PSTM. Ministério das Cidades e Ministério dos Transportes.

CORRÊA, L. de M. Guia de Manaus: roteiro histórico e sentimental da cidade do Rio Negro. Rio de Janeiro, 1969.

CURITIBA, Prefeitura Municipal. Inventário e Balanço de Emissões de Gases de Efeito Estufa no Município de Curitiba. Relatório Síntese. 2013.2 Disponível em: http://multimidia.curitiba.pr.gov.br/2012/00118446. Acesso em: 12 mar 2017.

DEPARTAMENTO ESTADUAL DE TRÂNSITO - Secção Amazonas - DETRAN-AM. (2016). Dados da evolução da frota de veículos automotores de Manaus. Comunicação pessoal.

DUTRA, J.; RELVAS, H.; OLIVEIRA, J.; DUTRA, M.; LOPES, M. Indicadores Socioambientais do Transporte Público como instrumento de avaliação da eficiência social do sistema. Trabalho apresentado ao XIX Encontro da Rede de Estudos Ambientais em Países de Língua Portuguesa - REALP. Fortaleza, 12 a 15/09/2017.

ELETROBRAS - AMAZONAS ENERGIA. (2016). Dados do sistema de geração de energia elétrica do sistema do Estado do Amazonas. Comunicação pessoal

FORTALEZA, Prefeitura Municipal. Inventário de Emissões de GEE do Município de Fortaleza. 2012. Disponível em:

http://www.fortaleza.ce.gov.br/sites/default/files/inventario_da_emissao_dos_gases_do_efeito_estufa. Acesso em 17 mar de 2017

INSTITUTO BRASILEIRO DE GEOGRAFIA E ESTATÍSTICA - IBGE. (2017). Disponivel em: http://www.igbe.gov.br. Cidades. Acessado em 05/03/2018.

INTERGOVERNMENTAL PANEL ON CLIMATE CHANGE - IPCC. (2006). Good Practice Guidance and Uncertainty Management in National Greenhouse Inventories - Revised 1996 IPCC Guidelines for National Greenhouse Gas Inventories. 
INTERGOVERNMENTAL PANEL ON CLIMATE CHANGE - IPCC. (2006). Guidelines for National Greenhouse Gas Inventories - The reference Manual - Volume 2 - Energy - IGES - Kanagawa.

MACHADO, L.; PICCININI, L. Os desafios para a efetividade da implementação dos planos de mobilidade urbana: uma revisão sistemática. Urbe. Revista Brasileira de Gestão Urbana (Brazilian Journal of Urban management), jan/abr., 10(1), 72-94, 2018.

MOTA, Danilo de Ávila; TAVARES, Paulo Henrique Gonçalves; PIRES, Heverton Fernando; PEREIRA, Sidinei Aparecido. Transporte Rodoviário e Poluição Ambiental. Revista Eletrônica FACP, ano II, $n^{\circ}$ 03, junho de 2013.

NEVES, C.; Yasmini, B. Análise de Metodologias de Produção de Inventários de Gases de Efeito Estufa de Cidades/ Camila Garcia Neves e Yasmini Bianor Canali Dopico- Rio de Janeiro: UFRJ/ Escola Politécnica, 2013.

OLIVEIRA, J. P. V. de. Manaus: Plano Diretor e expansão urbana. Dissertação apresentada ao Programa de Pós-Graduação em Sociedade e Cultura na Amazônia. Manaus: Universidade Federal do Amazonas, 2002.

PLANO DE MOBILIDADE URBANA - PlanMob. (2015). Disponível em http://smtu.manaus.am.gov.br/planmob/. Acessado em 07/12/2017.

POLÍTICA NACIONAL DE MOBILIDADE URBANA - PNMU. (2012). Lei 12.587 de 03/01/2012. Disponível em http://www.planalto.gov.br/ccivil_03/. Acessado em 07/11/2017

RECIFE (2015), Prefeitura Municipal. $1^{\circ}$ Inventário de Emissões de Gases de Efeito Estufa para a Cidade do Recife. Disponível em:

http://carbonn.org/uploads/tx_carbonndata/anexo\%201\%20Invent\%C3\%A1rioRecife_DS_20mar14_Luiz. Acesso em 17 mar 2017

SALVADOR, Prefeitura Municipal. Inventário de Emissões dos Gases do Efeito Estufa de Salvador. 2013. Disponível em: http://www.sustentabilidade.salvador.ba.gov.br/wpcontent/uploads/2016/06/inventario-de-emissoes-de-gases-final-compressed.pdf?download=1. Acesso 18 mar 2017.

SÃO PAULO. Inventário de Emissões de Gases de Efeito Estufa do Município de São Paulo. 2009. Disponível em:

http://www.prefeitura.sp.gov.br/cidade/secretarias/upload/sintesedoinventario_1250796710. Acesso em 15 mar 2017.

SBD/FEA/USP. (2010). Economia da Mudança do Clima no Brasil: custos e oportunidades / editado por Sérgio Margilus e Carolina Burle Schimidt Dubeux. São Paulo: IBEP Gráfica.

SMTU - Superintendência Municipal de Transportes Urbanos. (2016). Dados do sistema de transporte público por ônibus de Manaus. Comunicação pessoal.

SARGES, M. N. Belém: riquezas produzindo a Belle-Époque (1870-1912). Belém: Paka-Tatu, 2000.

VIANNA, J. N. S.; DUARTE, L. M. G.; WEHRMANN, M. E. S. F. O papel do etanol na mitigação das emissões de poluentes no meio urbano. II Jornada Luso-Brasileira de Ensino e Tecnologia em Engenharia - JBLE, 2009.

VILLAÇA, F. As Ilusões do Plano Diretor. São Paulo: USP, 2005. 